\title{
Evaluation of a Gadolinium-Based Nanoparticle (AGulX) for Contrast-Enhanced MRI of the Liver in a Rat Model of Hepatic Colorectal Cancer Metastases at 9.4 Tesla
}

\section{Evaluation eines Gadolinium-basierten Nanopartikels (AGuIX) zur kontrastmittelverstärkten MRT der Leber in Ratten mit hepatischen Metastasen eines kolorektalen Karzinoms bei 9,4 Tesla}

Authors

Affiliations
P. Fries ${ }^{1}$, D. Morr ${ }^{1}$, A. Müller ${ }^{1}$, F. Lux² , O. Tillement ${ }^{2}$, A. Massmann', R. Seidel ${ }^{1}$, T. Schäfer ${ }^{3}$, M. D. Menger ${ }^{4}$, G. Schneider ${ }^{1}$, A. Bücker ${ }^{1}$

Clinic of Diagnostic and Interventional Radiology, Saarland University Medical Center, Homburg, Germany Laboratoire de Physico-Chimie des Matériaux Luminescents, Université Claude Bernard, Lyon, France Department of General, Visceral and Pediatric Surgery, Saarland University Medical Center, Homburg, Germany Institute for Clinical and Experimental Surgery, Saarland University Medical Center, Homburg, Germany

\author{
Key words \\ - MR imaging \\ - abdomen \\ - metastases \\ - contrast agents \\ - gadolinium \\ - experimental study
}

received $\quad 17.1 .2015$ accepted 29.6.2015

\section{Bibliography}

DOI http://dx.doi.org/

10.1055/s-0035-1553500

Published online: 11.9.2015

Fortschr Röntgenstr 2015; 187:

1108-1115 @ Georg Thieme

Verlag KG Stuttgart · New York .

ISSN 1438-9029

\section{Correspondence \\ Dr. Peter Fries}

Clinic of Diagnostic and Interventional Radiology,

Saarland University

Medical Center

Kirrberger Str.

66421 Homburg

Germany

Tel.: ++ 49/6841/1624600 Fax: ++ 49/6841/1 624696

drpeterfries@googlemail.com

\section{Zusammenfassung \\ $\nabla$}

Ziel: Vergleich eines Gd-basierten Nanopartikels (AGuIX) mit einem extrazellulären, niedermolekularen Kontrastmittel (Gd-DOTA) zur MRT der Leber bei 9,4 $\mathrm{T}$ in Ratten mit hepatischen Metastasen eines kolorektalen Karzinoms.

Material und Methoden: 12 Ratten mit hepatischen Metastasen wurden mittels eines 9,4T Tierscanners untersucht. Es wurden T1-gewichtete FLASH-Sequenzen $(\mathrm{TR} / \mathrm{TE}=45 / 2,5 \mathrm{~ms}$, Flipwinkel $=45^{\circ}, \mathrm{TA}=1: 23 \mathrm{~min}, \mathrm{FOV}=5,12 \times 5,12$ $\mathrm{cm} 2$, Matrix $=256 \times 256$ ) vor und an 10 Zeitpunkten nach KM-Gabe mittels Selbstgating akquiriert. Jedes Versuchstier erhielt $0,1 \mathrm{mmol} / \mathrm{kg}$ KG GdDOTA i. v. Zwei Tage später wurden die Untersuchungen nach Gabe von 0,01 mmol/kg KG AGuIX (entsprechend identischen Dosierungen an Gd) wiederholt. SNR von normalem Lebergewebe (SNRliver), stark und gering KM-affinen Anteilen der Tumoren (SNRtumor, hyperenh/SNRtumor, hypoenhanc), des Musculus erector spinae (SNRmuscle), CNR und Läsionsenhancement (LE) wurden basierend auf ROI-Messungen berechnet. Ergebnisse: Die Mittelwerte des SNRliver (GdDOTA: 14,6+/-0,7; AGuIX: 28,2+/-2,6; p<0,001), SNRtumor, hyperenhanc (Gd-DOTA: 18,6+/-1,2; AGuIX: 29,6+/-2,8, $\mathrm{p}<0,001)$, SNRtumor, hypoenhanc (Gd-DOTA: 12,0+/-0,7; AGuIX: 15,4+/$0,7, \mathrm{p}<0,001$ ), SNRmuscle (Gd-DOTA: 12,3+/0,3; AGuIX: $14,0+\mid-0,7, \mathrm{p}<0,001$ ), des CNR (GdDOTA: $-2,5+/-0,2$; AGuIX: $-7,5+\mid-1,0, \mathrm{p}<0,001$ ) und des LE (Gd-DOTA: 3,8+/-0,7; AGuIX: 14,9+/$2,8 / p=0,001$ ) waren nach Gabe von AGuIX signifikant höher. Trotz der höheren Molekülmasse zeigt AGuIX analog zum niedermolekularen Komplex Gd-DOTA eine maximale Signalanreicherung unmittelbar nach Injektion gefolgt von einem kontinuierlichen Auswaschen.

Schlussfolgerungen: AGuIX zeigt ein besseres Enhancement als Gd-DOTA bei identischer Gd-Dosierungen. Dies basiert auf der Molekülstruktur

\section{Abstract \\ $\nabla$}

Purpose: The aim of this study was to compare a Gd-based nanoparticle (AGuIX) with a standard extracellular Gd-based contrast agent (Gd-DOTA) for MRI at 9.4 $\mathrm{T}$ in rats with hepatic colorectal cancer metastases.

Materials and Methods: 12 rats with hepatic metastases were subjected to MRI using a 9.4T animal scanner. $\mathrm{T} 1 \mathrm{w}$ self-gated FLASH sequences $(\mathrm{TR} / \mathrm{TE}=$ $45 / 2.5 \mathrm{~ms}$, alpha $=45^{\circ}, \mathrm{TA}=1: 23 \mathrm{~min}, \mathrm{FOV}=5.12 \times$ $5.12 \mathrm{~cm}^{2}$, matrix $=256 \times 256$ ) were acquired before and at 10 time points after contrast injection. Each animal received $0.1 \mathrm{mmol} / \mathrm{kg}$ BW Gd-DOTA i.v. 2 days later AGuIX was applied at $0.01 \mathrm{mmol} / \mathrm{kg}$ BW (representing equal Gd doses). The SNR of normal liver (SNRliver), hyper- and hypoenhancing parts of tumors (SNRtumor, hyperenh/SNRtumor, hypoenhanc), erector spinae muscle (SNRmuscle), CNR and lesion enhancement (LE) were calculated based on ROI measurements.

Results: Mean SNRliver (Gd-DOTA: 14.6+/-0.7; AGuIX: 28.2+/-2.6, $\mathrm{p}<0.001)$, SNRtumor, hyperenhanc (Gd-DOTA: 18.6+/-1.2; AGuIX: 29.6+/2.8, $\mathrm{p}<0.001$ ), SNRtumor, hypoenhanc (GdDOTA: $12.0+/-0.7$; AGuIX: $15.4+\mid-0.7, \mathrm{p}<0.001$ ), SNRmuscle (Gd-DOTA: $12.3+/-0.3$; AGuIX: 14.0 + -0.7, p < 0.001), mean CNR (Gd-DOTA: $-2.5+/-$ 0.2 ; AGuIX: $-7.5+/-1.0, \mathrm{p}<0.001$ ) and LE (GdDOTA: $3.8+/-0.7$; AGuIX: $14.9+\mid-2.8, \mathrm{p}=0.001$ ) were significantly higher using AGuIX. Regardless of the larger molecular size, AGuIX demonstrates an early peak enhancement followed by a continuous washout.

Conclusion: AGuIX provides better enhancement at 9.4 $\mathrm{T}$ compared to Gd-DOTA for equal doses of applied Gd. This is based on the molecule structure and the subsequent increased interaction with protons leading to a higher relaxivity. AGuIX potentially ameliorates the conspicuity of focal liver lesions and may improve the sensitivity in diagnostic imaging of malignant hepatic tumors. 
und der konsekutiv verbesserten Interaktion mit Protonen, was zu einer Erhöhung der Relaxivität führt. AGuIX kann potenziell die Erkennbarkeit fokaler Leberläsionen und damit die Sensitivität bei der Diagnostik maligner Lebertumoren verbessern.

Kernaussagen:

- AGuIX zeigt bei 9,4T bessere Kontrasteigenschaften im Vergleich zu dem extrazellulären Kontrastmittel Gd-DOTA.

- AGuIX kann dazu beitragen die Detektion fokaler Leberläsionen und damit auch die Sensitivität der MRT bei malignen Raumforderungen der Leber zu verbessern.

- Aufgrund der geringen Molekülgröße wird AGuIX schnell renal ausgeschieden und zeigt keine unerwünschte Akkumulation im Körper.
Key Points:

- AGuIX provides superior enhancement as compared to the extracellular compound Gd-DOTA at 9.4T.

- AGuIX may improve the detection and diagnostic sensitivity of malignant focal liver lesions.

- The small size of AGuIX allows for fast renal clearance and prevents undesirable accumulation in the body.

Citation Format:

- Fries P, Morr D, Müller A et al. Evaluation of a Gadolinium-Based Nanoparticle (AGuIX) for Contrast-Enhanced MRI of the Liver in a Rat Model of Hepatic Colorectal Cancer Metastases at 9.4 Tesla. Fortschr Röntgenstr 2015; 187: 1108-1115

\section{Introduction}

$\nabla$

In recent years, the development and application of nanoparticles in biomedicine have increasingly become a topic of research. Especially in the setting of so-called "theragnostics", nanoparticles are used as multifunctional compounds. They may serve as contrast agents for different imaging techniques including scintigraphy, optical imaging, ultrasound, X-ray-based imaging or magnetic resonance imaging. In addition, they are used as therapeutic compounds for different modalities such as sensitizing for radiotherapy, hyperthermia, and drug delivery [1 - 3]. One important prerequisite for the clinical application of nanoparticles is biocompatibility. In this context, the particles should not be toxic and should demonstrate a sufficiently fast and efficient clearance from the body. Hence, the size of the molecule plays a crucial role. In order to avoid uptake and accumulation of nanoparticles in macrophages and other cells of the reticuloendothelial system, the hydrodynamic diameter should be smaller than $50 \mathrm{~nm}$ [4]. Beyond this, a fast renal clearance is only achieved if the particle size does not exceed $5.5 \mathrm{~nm}$ [5]. However, it is still challenging to design nanoparticles combining both multifunctionality and an adequately small size.

Recent technical achievements allowed building polysiloxanebased nanomolecules with hydrodynamic diameters between 3 and $7 \mathrm{~mm}$ demonstrating multifunctional features [6]. Another approach for building sufficiently small nanoparticles is based on so-called "small rigid platforms" consisting of a polysiloxane core grafted to $10 \mathrm{Gd}$-DOTA species via amide functions in the periphery. Among other functionalities, these nanoparticles demonstrate high $\mathrm{r} 1$ relaxivities and, thus, may serve as a highly potent MRI contrast agent [7].

The aim of this study was to evaluate signal-to-noise ratio (SNR), contrast-to-noise ratio (CNR) and lesion enhancement (LE) of the Gd-based nanoparticle AGuIX compared to a standard extracellular contrast agent (Gd-DOTA) for equal doses of injected gadolinium at $9.4 \mathrm{~T}$ in a rat liver model of colon cancer metastases.

\section{Materials and Methods}

All experiments performed in this study were approved by the local Institutional Animal Care and Use Committee and were performed according to the National Institutes of Health Guidelines for Care and Use of Laboratory Animals.

\section{Tumor model}

We included 12 female rats (WAG-Rij, Charles River Laboratories, Sulzfeld, Germany) with a mean weight \pm SD of $152 \pm 9 \mathrm{~g}$ in this study. Food and water was provided ad libitum before and after the experiments.

General anesthesia was performed for all surgical procedures and MRI examinations by applying a mixture of $2-4 \%$ isoflurane and $96-98 \%$ oxygen by an animal nose mask at a flow rate of $1-3 \mathrm{l} / \mathrm{min}$. In order to achieve analgesia during surgery, we injected $5 \mathrm{mg} / \mathrm{kg}$ body weight Carprofen subcutaneously.

After a midline incision of the abdominal wall, a syngeneic colon cancer cell suspension ( $5 \times 10^{5}$ tumor cells (CC531, CLS; Cell Lines Service and Tumor-Cellbank, Heidelberg, Germany) was injected into the left hepatic lobe using a tuberculin syringe with a $27 \mathrm{G}$ needle. In order to prevent bleeding and intraperitoneal recoil of tumor cells, the injection site was compressed for 5 minutes. Subsequently, the abdominal cavity was closed by continuous suture (Vicryl 4-0, Johnson \& Johnson Medical, Norderstedt, Germany). Following the MRI examinations, all animals were sacrificed and the livers were harvested for histological evaluation. All liver specimens were examined after fixation and hematoxylin and eosin (H\&E) staining.

\section{Contrast agents}

The physicochemical properties of the applied contrast agents are shown in $\bullet$ Table 1.

The investigational contrast agent AGuIX was provided by a cooperating research group (co-authors F. L. and O.T.), who initially described this compound [7]. AGuIX consists of a polysiloxane

Table 1 Physicochemical properties of the applied contrast agents.

Tab. 1 Physikochemische Eigenschaften der applizierten Kontrastmittel.

\begin{tabular}{|c|c|c|c|c|c|c|c|}
\hline & $\begin{array}{l}\text { MW } \\
\text { (kDa) }\end{array}$ & Gd ions & $\begin{array}{l}\text { hydro-dynamic } \\
\text { diameter }\end{array}$ & $\begin{array}{l}\text { blood half } \\
\text { life }\end{array}$ & $\begin{array}{l}\text { thermodynamic stability } \\
\text { constant }\left(\log \beta_{110}\right)\end{array}$ & $\begin{array}{l}r_{1} / r_{2} @ 1.5 T \\
\left(\mathrm{mM}^{-1} \mathrm{~s}^{-1}\right)\end{array}$ & $\begin{array}{l}r_{1} / r_{2} @ 9.4 T \\
\left(\mathrm{mM}^{-1} \mathrm{~s}^{-1}\right)\end{array}$ \\
\hline Gd-DOTA & 0.56 & 1 & $1 \mathrm{~nm}$ & $6.8 \mathrm{~min}$ & $25.58(\operatorname{Ref} 4)^{1}$ & $3.6 / 4.3$ & $3.1 / 3.9$ \\
\hline AGulX & 8.4 & 10 & $3 \mathrm{~nm}$ & $13.2 \mathrm{~min}$ & $24.78(\operatorname{Ref} 4)^{1}$ & 11.4 / 13.2 & $5.8 / 22.9$ \\
\hline
\end{tabular}

MW (molecular weight); $r_{1} / r_{2}\left(r_{1} / r_{2}\right.$ relaxivities per $\mathrm{Gd}^{3+}, 37^{\circ} \mathrm{C}, 4 \%$ human albumin serum).

${ }^{1}$ thermodynamic stability constant assessed by potentiometric measurements 
core grafted to $10 \mathrm{Gd}$-DOTA species via amide functions in the periphery ( $\bullet$ Fig. 1 ). It has a rather small molecular mass of 8.5 $+/-1 \mathrm{kDa}$ with a mean hydrodynamic diameter of 3.0+/-0.1 nm. The rather small size of AGuIX may be achieved by using a topdown process for chemical synthesis of the compound as recently described in detail [4]. In a first step gadolinium oxide cores are obtained by addition of soda on gadolinium trichloride previously dissolved in diethylene glycol (DEG). Then, a polysiloxane shell is formed by a sol gel process with the addition of the silane precursors APTES ((3-aminopropyl) triethoxysilane) and TEOS (tetraethyl orthosilicate). DOTA derivatives are then grafted covalently to the polysiloxane shell by an amide bond in DEG. The topdown process occurs during the transfer of the nanoparticles from DEG to water with dissolution of the gadolinium oxide core and chelation of the gadolinium ions by the ligands.

The small size of AGuIX allows for fast renal clearance with a blood half-life time of $13.2 \mathrm{~min}$ [7]. In addition, it is too small to be taken up by macrophages of the reticulo-endothelial system, thus, it does not accumulate in the liver, bowel or lung.

At $1.5 \mathrm{~T}$, AGuIX demonstrates an $\mathrm{r} 1$ relaxivity higher than all commercially available Gd-based contrast agents at present ( $\bullet$ Table 1). However, with an increasing field strength, $r 1$ demonstrates a decay, which is a common effect of macromolecular contrast agents at high magnetic fields [8]. In this study AGuIX was intraindividually compared to Gd-DOTA, which is a part of the nanomolecule itself. Thus, the dose of AGuIX administered here was reduced by a factor of ten in order to achieve equal doses of injected gadolinium.

Gd-DOTA (DOTAREM ${ }^{\circledR}$, Guerbet, France) was used as a reference contrast agent in this study. It is a gadolinium-based, low molecular weight $(0.56 \mathrm{kDa})$ compound with extracellular distribution showing a fast elimination by glomerular filtration. It is approved

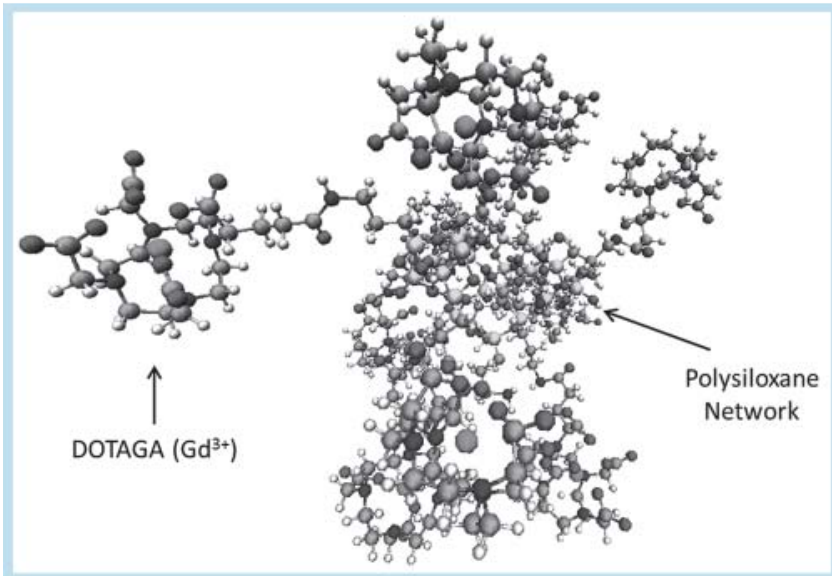

Fig. 1 Three-dimensional molecular representation of AGulX consisting of a polysiloxane core linked to ten Gd-DOTA complexes in the periphery.

Abb. 1 Dreidimensionale Darstellung der Molekülstruktur von AGuIX bestehend aus einem Polysiloxan-Kern mit zehn Gd-DOTA-Komplexe in der Peripherie. for a wide spectrum of clinical applications in humans. The relaxivities of Gd-DOTA are lower than AGuIX for both clinical and ultrahigh field strengths $[9,10]$ ( $\bullet$ Table 2 ). Gd-DOTA was administered at a clinical dose of $0.1 \mathrm{mmol} / \mathrm{kg}$ body weight.

\section{MR Imaging}

Magnetic resonance imaging (MRI) was performed 14 days after tumor cell injection using a horizontal bore 9.4 Tesla MRI animal scanner (Bruker BioSpin 94/20, Ettlingen, Germany) equipped with a 16-channel transmit-receive volume coil.

All MRI experiments were performed under general anesthesia using a mixture of isoflurane and oxygen as described above. We used a dedicated animal cradle with the rats being placed in a prone position. The respiratory rate of the animals was monitored using a small pressure transducer (Graseby infant respiration sensor, Smith Medical Germany, Grasbrunn, Germany) attached to the abdominal wall. A rectal sensor measured the core temperature of the animals during the MRI procedure. Physiological data were processed and monitored using an external computer with dedicated software (PC-SAM32, Sa Instruments Inc., Stony Brook, NY, USA). Application of eye ointment prevented ocular desiccation.

Detailed parameters of the MRI sequences are given in $\bullet$ Table 2. We acquired T2-weighted fast spin echo sequences for lesion detection within the left liver lobe ( $\bullet$ Fig. 2 ). Subsequently, axial T1-weighted sequences covering the area of the tumors were

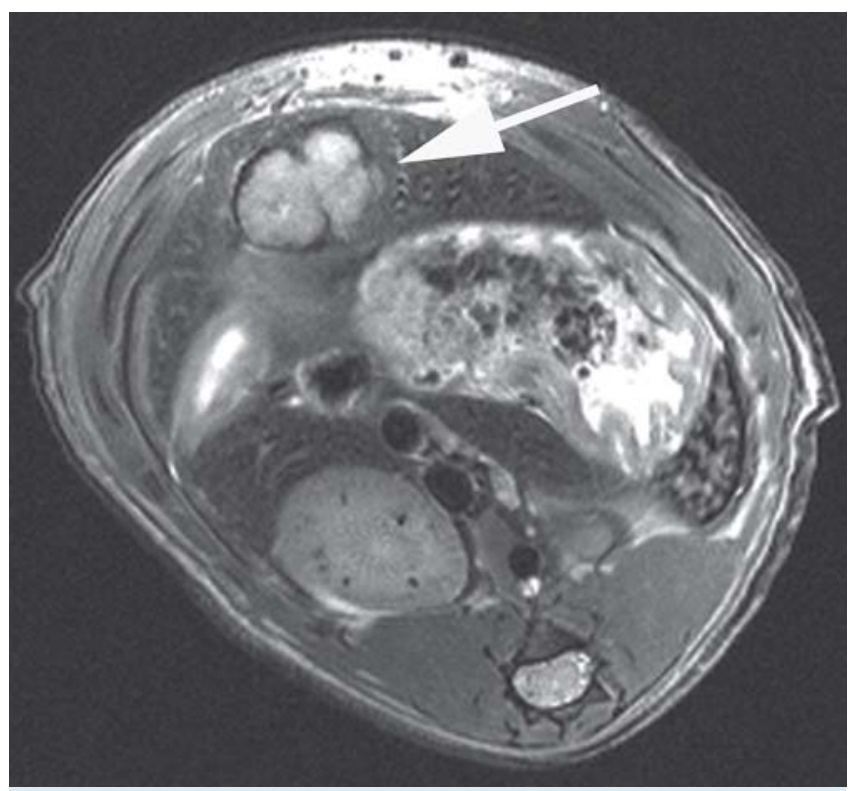

Fig. 2 T2-weighted fast spin echo sequence in axial orientation acquired for tumor detection in the rat liver. The experimentally implanted liver metastasis is well demarcated and appears hyperintense compared to the surrounding liver parenchyma (arrow).

Abb. 2 Axiale T2-gewichtete Fast-Spinecho-Sequenz akquiriert zur Detektion des Tumors in der Rattenleber. Die experimentell erzeugte Lebermetastase stellt sich hyperintens zum umgebenden Lebergewebe dar (Pfeil).

\begin{tabular}{|lllllllll} 
& TR & TE & flip angle & no. of averages & FoV & matrix & pixel size & $\begin{array}{l}\text { slice } \\
\text { thickness }\end{array}$ \\
\hline T2w FSE & 920 & 27 & $90^{\circ}$ & 3 & $50 \times 50 \mathrm{~mm}^{2}$ & $256 \times 256$ & $195 \times 195 \mu \mathrm{m}^{2}$ & $1 \mathrm{~mm}^{2}$ \\
\hline T1w FLASH & $45 \mathrm{~ms}$ & $2.5 \mathrm{~ms}$ & $45^{\circ}$ & 5 & $50 \times 50 \mathrm{~mm}^{2}$ & $256 \times 256$ & $195 \times 195 \mu \mathrm{m}^{2}$ & $1 \mathrm{~mm}^{2}$ \\
\hline
\end{tabular}

Table 2 Detailed parameters of the acquired sequences.

Tab. 2 Detaillierte Parameter der akquirierten Sequenzen. 


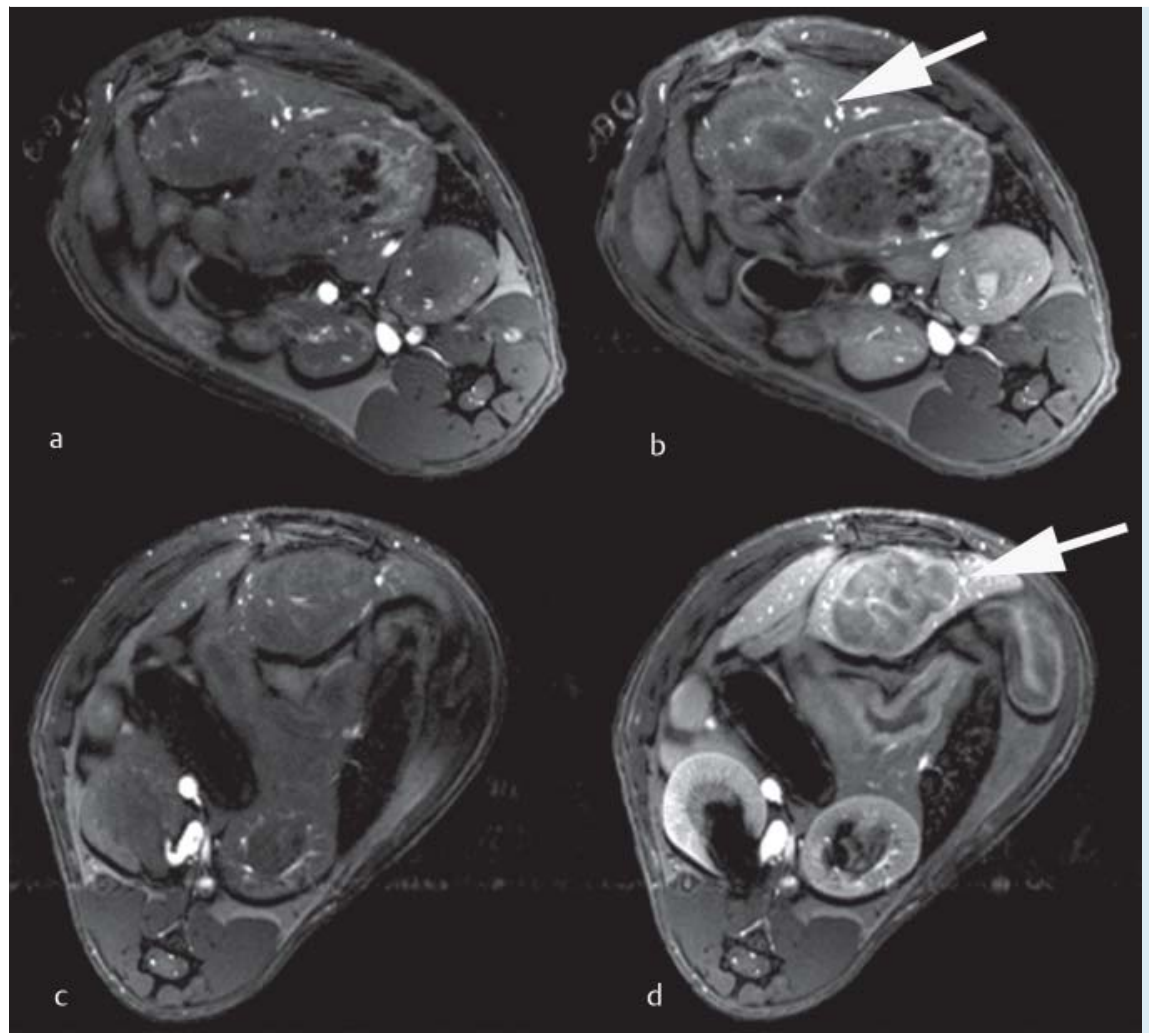

Fig. 3 Axial T1-weighted images of the hepatic metastasis before $\mathbf{a}$ and after the application of $0.1 \mathrm{mmol} / \mathrm{kg}$ BW Gd-DOTA $\mathbf{b}$. Note the relatively low signal intensity of the lesion on the unenhanced scan, which is improved after contrast administration. c, d display the corresponding unenhanced and contrast-enhanced T1-weighted images after the application of $0.01 \mathrm{mmol} / \mathrm{kg}$ BW AGulX. Note the markedly higher enhancement of the liver and the lesion using AGuIX as compared to Gd-DOTA.

Abb.3 Axiale T1-gewichtete Aufnahme der Lebermetastase vor a und nach Applikation von $0,1 \mathrm{mmol} / \mathrm{kg}$ Körpergewicht Gd-DOTA $\mathbf{b}$. Auf den Nativaufnahmen stellt sich die Läsion mit niedriger Signalintensität dar, die nach Gabe von Gd-DOTA geringfügig ansteigt. c, $\mathbf{d}$ zeigt die entsprechenden T1-gewichteten Aufnahmen vor und nach Gabe von $0,01 \mathrm{mmol} / \mathrm{kg}$ Körpergewicht AGulX. Es zeigt sich eine deutlich stärkere Signalanreicherung sowohl der Leber als auch der Raumforderung im Vergleich zu Gd-DOTA.

performed using a retrospectively self-gated FLASH technique (IntraGate ${ }^{\circledR}$ ). This acquisition scheme allows for the acquisition of respiratory-gated sequences of the abdomen based on a navigator approach under free respiration of the animal. Two sets of identical T1-weighted sequences were acquired in all animals, and mean as well as subtracted datasets were calculated for noise measurements. Following the acquisition of the unenhanced scans, $0.1 \mathrm{mmol} / \mathrm{kg}$ body weight Gd-DOTA were injected through a tail vein catheter ( $27 \mathrm{G}$ ). After contrast medium application, T1-weighted sequences were acquired at ten consecutive time points at the same slice position as the unenhanced scans ( 0 Fig. 3). Two days later the MRI experiments were repeated intraindividually by applying $0.01 \mathrm{mmol} / \mathrm{kg}$ body weight AGuIX. The contrast agent dose of AGuIX was decreased in relation to the extracellular compound to compensate for the ten times higher amount of Gd-DOTA complexes linked to the nanoparticle. Thus, all contrast-enhanced MRI studies were performed by applying equal doses of gadolinium. We decided to inject the extracellular contrast agent at the first examination time point and AGuIX at the second examination time point to prevent unpredictable interference of the nanoparticle-based contrast agent due to a longer circulation time in the body.

\section{MR Data Analysis}

Acquired image data were transferred to an external workstation and quantitatively analyzed using open-source image evaluation software (OsiriX, Pixmeo, Bernex, Switzerland). Based on regionof-interest (ROI) analyses, the signal intensities of normal liver tissue, homogeneously hyperenhancing and hypoenhancing parts of the induced liver tumors and the erector spinae muscles were measured for all unenhanced and contrast-enhanced sequences with the ROIs being placed in identical anatomic positions for each particular time point. The standard deviation of corresponding ROIs placed on subtracted datasets served as the background noise levels [11]. Signal-to-noise ratios (SNR) for normal liver parenchyma, hyperenhancing and hypoenhancing parts of the liver metastases as well as of the erector spinae muscle were calculated as:

$\mathrm{SNR}_{\text {liver }, \mathrm{t}}=\frac{\mathrm{SI}_{\text {liver, } \mathrm{t}} \bullet \sqrt{2}}{\mathrm{SD}_{\text {subtract, liver, }}}$

$\mathrm{SNR}_{\text {tumor,hyperenhanc.,t }}=\frac{\mathrm{SI}_{\text {tumor,hyperenhanc.t, }} \bullet \sqrt{2}}{\mathrm{SD}_{\text {subtract,tumor, hyperenhanc,t }}}$

$\mathrm{SNR}_{\text {tumor,hypoenhanc., }}=\frac{\mathrm{SI}_{\text {tumor,hypoenhanc,.t }} \cdot \sqrt{2}}{\mathrm{SD}_{\text {subtract,tumor, hypoenhanc,.t }}}$

$\mathrm{SNR}_{\text {muscle,t }}=\frac{\mathrm{SI}_{\text {muscle,t }} \bullet \sqrt{2}}{\mathrm{SD}_{\text {subtract,muscle,t }}}$

Contrast-to-noise ratios (CNR) between normal liver tissue and the hypoenhancing parts of the induced liver metastases were calculated as:

$\mathrm{CNR}_{\mathrm{t}}=\mathrm{SNR}_{\text {tumor,hypoenhanc.,t }}-\mathrm{SNR}_{\text {liver,t }}$

Lesion enhancement was calculated for the hyperenhancing parts of the liver metastases for both contrast agents and all time points as:

$\mathrm{LE}_{\mathrm{t}}=\mathrm{SNR}$ $-\mathrm{SNR}$

$\mathrm{SI}_{\text {tumor, hyperenhanc, t: }}$ signal intensity of the hyperenhancing parts of the tumor at unenhanced and contrast-enhanced time points $t$

$\mathrm{SI}_{\text {tumor, hypoenhanc, } \mathrm{t}}$ : signal intensity of a hypoenhancing aspect of the tumor at unenhanced and contrast-enhanced time points $t$

$\mathrm{SI}_{\text {liver, } \mathrm{t}}$ : signal intensity of the liver at unenhanced and contrastenhanced time points $t$

$\mathrm{SI}_{\text {muscle, } \mathrm{t}}$ : signal intensity of the muscle at unenhanced and contrast-enhanced time points $t$

$\mathrm{SD}_{\text {subtract }}$ : standard deviation of the subtracted unenhanced dataset representing the background noise 


\section{Statistical Analysis}

Statistical analyses were performed with commercially available software (GraphPad Prism version 5.00, GraphPad Software, San Diego, California, USA). The presence of Gaussian distribution for the different data groups was evaluated with a D'Agostino and Pearson normality test. Statistically significant differences of SNR, CNR, and LE between the two different contrast agents were assessed with a paired t-test or a Wilcoxon test where appropriate with $\mathrm{p}<0.05$ considered statistically significant. All data are given as means $+/$ - standard deviation (SD).

\section{Results}

All surgical procedures and contrast agent applications were successful in all twelve animals included in this study. Subsequently, all acquired MRI data could be included for evaluation. Histological analysis of liver specimens confirmed the presence of solid hepatic metastases in all examined animals without signs of necrosis (๑ Fig. 4).

\section{Assessment of Enhancement Properties}

Detailed SNR data are provided in $\bullet$ Table $\mathbf{3}$ with representative graphs given in $\bullet$ Fig. 5,6 . Normal liver tissue demonstrated significantly higher SNR using AGuIX (mean+/-SD: SNR mean, liver (AGuIX): $28.2+\mid-2.6$ ) as compared to Gd-DOTA (SNR mean, liver $(\mathrm{Gd}-$ DOTA): $14.6+/-0.8 ; \mathrm{p} \leq 0.001$ for all examination time points). Both agents showed an early peak of enhancement in the normal liver parenchyma immediately after application followed by a continuous decrease during the examination period. SNR values of the hyperenhancing parts of the hepatic tumors were markedly higher for the nanoparticle ( $\mathrm{SNR}_{\text {mean, tumor, hyperenhanc. }}$ (AGuIX): $29.6+\mid-2.8$ ) as compared to Gd-DOTA (SNR mean, tumor, hyperenhanc. (Gd-DOTA): $18.6+/-1.2 ; \mathrm{p} \leq 0.001$ for all contrast-enhanced time
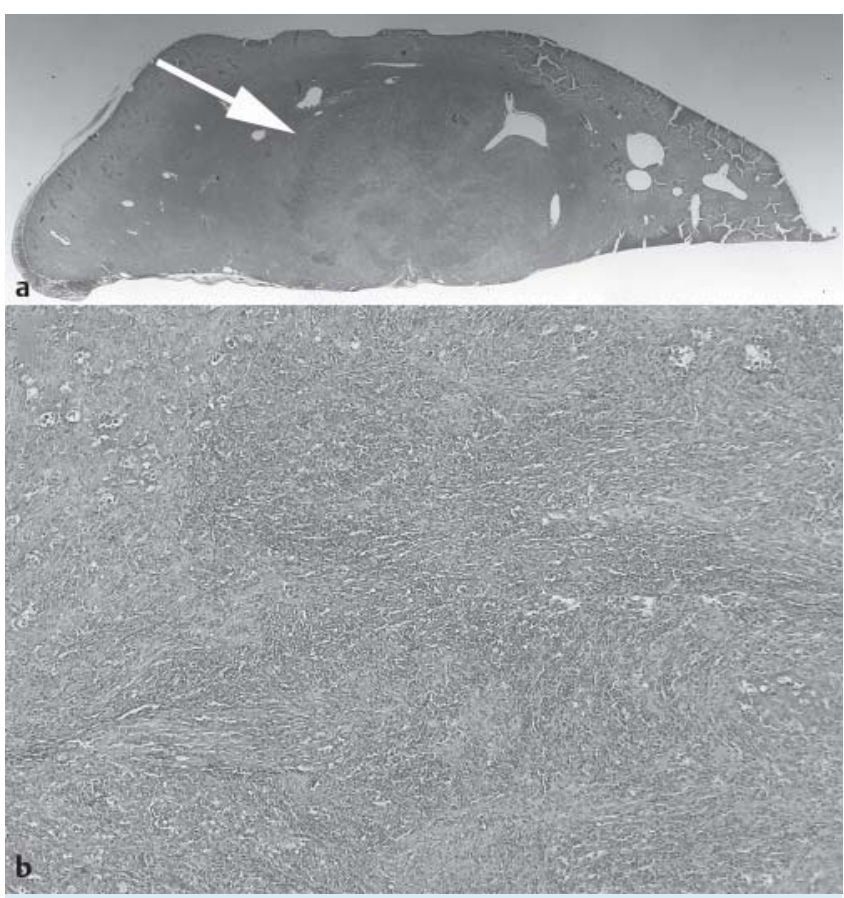

Fig. 4 a demonstrates a liver specimen after hematoxylin and eosin staining (20x magnification) with a well-defined metastasis in the left liver lobe (arrow). 100x magnification of the corresponding liver specimen b shows an infiltrate of colon cancer cells adjacent to a fibrotic stroma within an inflammatory background.

Abb. 4 a zeigt den histologischen Schnitt der Leber nach HämatoxylinEosin-Färbung (20-fache Vergrößerung) mit einer scharf berandeten Metastase im linken Leberlappen (Pfeil). Die 100-fache Vergrößerung des korrespondierenden Schnittes zeigt neben Tumorzellverbänden auch fibrotisches Stroma und Infiltrationen mit Entzündungszellen.

Table 3 SNR comparison for different locations before (unenhanced) and at different time points after intravenous administration of the two different contrast agents.

Tab. 3 Vergleich des SNR für unterschiedliche Lokalisationen vor und nach intravenöser Applikation der beiden Kontrastmittel (Mittelwerte $+/-$ Standardabweichung).

\begin{tabular}{|c|c|c|c|c|c|c|c|c|c|c|c|c|}
\hline & & Unenh. & $2 \mathrm{~min}$ & $4 \mathrm{~min}$ & $6 \mathrm{~min}$ & $8 \mathrm{~min}$ & $10 \mathrm{~min}$ & $12 \mathrm{~min}$ & $14 \mathrm{~min}$ & $16 \mathrm{~min}$ & $18 \mathrm{~min}$ & $20 \mathrm{~min}$ \\
\hline \multirow[t]{3}{*}{ liver } & Gd-DOTA & $\begin{array}{l}13.6 \\
( \pm 2.3)\end{array}$ & $\begin{array}{l}15.6 \\
( \pm 3.5)\end{array}$ & $\begin{array}{l}15.1 \\
( \pm 3.1)\end{array}$ & $\begin{array}{l}15.4 \\
( \pm 3.1)\end{array}$ & $\begin{array}{l}14.8 \\
( \pm 2.8)\end{array}$ & $\begin{array}{l}14.4 \\
( \pm 2.7)\end{array}$ & $\begin{array}{l}14.5 \\
( \pm 2.5)\end{array}$ & $\begin{array}{l}14.1 \\
( \pm 3.2)\end{array}$ & $\begin{array}{l}14.5 \\
( \pm 3.5)\end{array}$ & $\begin{array}{l}14.1 \\
( \pm 3.2)\end{array}$ & $\begin{array}{l}13.4 \\
( \pm 2.9)\end{array}$ \\
\hline & AGulX & $\begin{array}{l}14.1 \\
( \pm 4.2)\end{array}$ & $\begin{array}{l}32.9 \\
( \pm 8.8)\end{array}$ & $\begin{array}{l}31.7 \\
( \pm 8.4)\end{array}$ & $\begin{array}{l}29.3 \\
( \pm 7.2)\end{array}$ & $\begin{array}{l}29.4 \\
( \pm 7.2)\end{array}$ & $\begin{array}{l}27.9 \\
( \pm 6.8)\end{array}$ & $\begin{array}{l}27.1 \\
( \pm 6.4)\end{array}$ & $\begin{array}{l}26.9 \\
( \pm 6.4)\end{array}$ & $\begin{array}{l}25.9 \\
( \pm 6.3)\end{array}$ & $\begin{array}{l}25.6 \\
( \pm 6.2)\end{array}$ & $\begin{array}{l}25.2 \\
( \pm 6.3)\end{array}$ \\
\hline & $\mathrm{p}$ & 0.65 & $<0.001$ & $<0.002$ & $<0.001$ & $<0.001$ & $<0.001$ & $<0.001$ & $<0.001$ & $<0.001$ & $<0.001$ & $<0.001$ \\
\hline \multirow{3}{*}{$\begin{array}{l}\text { tumor } \\
\text { hyper- } \\
\text { enhanc. } \\
\text { part }\end{array}$} & Gd-DOTA & $\begin{array}{l}12.3 \\
( \pm 3.3)\end{array}$ & $\begin{array}{l}20.6 \\
( \pm 5.7)\end{array}$ & $\begin{array}{l}20.0 \\
( \pm 6.0)\end{array}$ & $\begin{array}{l}19.5 \\
( \pm 5.4)\end{array}$ & $\begin{array}{l}18.7 \\
( \pm 5.3)\end{array}$ & $\begin{array}{l}18.4 \\
( \pm 4.8)\end{array}$ & $\begin{array}{l}18.4 \\
( \pm 4.5)\end{array}$ & $\begin{array}{l}18.2 \\
( \pm 5.0)\end{array}$ & $\begin{array}{l}17.9 \\
( \pm 4.0)\end{array}$ & $\begin{array}{l}17.9 \\
( \pm 4.6)\end{array}$ & $\begin{array}{l}16.6 \\
( \pm 4.3)\end{array}$ \\
\hline & AGulX & $\begin{array}{l}14.7 \\
( \pm 3.8)\end{array}$ & $\begin{array}{l}34.7 \\
( \pm 7.5)\end{array}$ & $\begin{array}{l}33.3 \\
( \pm 7.0)\end{array}$ & $\begin{array}{l}30.9 \\
( \pm 5.8)\end{array}$ & $\begin{array}{l}30.9 \\
( \pm 5.8)\end{array}$ & $\begin{array}{l}29.3 \\
( \pm 5.6)\end{array}$ & $\begin{array}{l}28.4 \\
( \pm 5.2)\end{array}$ & $\begin{array}{l}28.2 \\
( \pm 5.2)\end{array}$ & $\begin{array}{l}27.2 \\
( \pm 5.4)\end{array}$ & $\begin{array}{l}26.8 \\
( \pm 5.3)\end{array}$ & $\begin{array}{l}26.4 \\
( \pm 5.4)\end{array}$ \\
\hline & $\mathrm{P}$ & 0.07 & $<0.001$ & $<0.001$ & $<0.001$ & $<0.001$ & $<0.001$ & $<0.001$ & $<0.001$ & $<0.001$ & $<0.001$ & $<0.001$ \\
\hline \multirow{3}{*}{$\begin{array}{l}\text { tumor } \\
\text { hypo- } \\
\text { enhanc. } \\
\text { part }\end{array}$} & Gd-DOTA & $9.5( \pm 1.7)$ & $\begin{array}{l}13.2 \\
( \pm 2.8)\end{array}$ & $\begin{array}{l}12.7 \\
( \pm 2.9)\end{array}$ & $\begin{array}{l}12.8 \\
( \pm 2.5)\end{array}$ & $\begin{array}{l}12.1 \\
( \pm 2.5)\end{array}$ & $\begin{array}{l}11.8 \\
( \pm 2.1)\end{array}$ & $\begin{array}{l}11.9 \\
( \pm 2.3)\end{array}$ & $\begin{array}{l}11.7 \\
( \pm 2.5)\end{array}$ & $\begin{array}{l}11.2 \\
( \pm 2.2)\end{array}$ & $\begin{array}{l}11.2 \\
( \pm 2.1)\end{array}$ & $\begin{array}{l}11.1 \\
( \pm 2.1)\end{array}$ \\
\hline & AGulX & $\begin{array}{l}11.0 \\
( \pm 2.1)\end{array}$ & $\begin{array}{l}16.5 \\
( \pm 4.3)\end{array}$ & $\begin{array}{l}16.5 \\
( \pm 4.0)\end{array}$ & $\begin{array}{l}15.5 \\
( \pm 2.9)\end{array}$ & $\begin{array}{l}15.5 \\
( \pm 2.8)\end{array}$ & $\begin{array}{l}15.3 \\
( \pm 2.5)\end{array}$ & $\begin{array}{l}15.0 \\
( \pm 2.4)\end{array}$ & $\begin{array}{l}15.1 \\
( \pm 2.4)\end{array}$ & $\begin{array}{l}15.1 \\
( \pm 2.5)\end{array}$ & $\begin{array}{l}14.6 \\
( \pm 2.5)\end{array}$ & $\begin{array}{l}14.6 \\
( \pm 2.8)\end{array}$ \\
\hline & $\mathrm{p}$ & 0.34 & 0.11 & 0.06 & 0.07 & 0.03 & 0.01 & 0.01 & 0.01 & 0.004 & 0.001 & 0.001 \\
\hline \multirow[t]{3}{*}{ muscle } & Gd-DOTA & $\begin{array}{l}11.4 \\
( \pm 1.7)\end{array}$ & $\begin{array}{l}13.0 \\
( \pm 2.0)\end{array}$ & $\begin{array}{l}12.7 \\
( \pm 2.1)\end{array}$ & $\begin{array}{l}12.5 \\
( \pm 2.1)\end{array}$ & $\begin{array}{l}12.3 \\
( \pm 2.2)\end{array}$ & $\begin{array}{l}12.5 \\
( \pm 2.0)\end{array}$ & $\begin{array}{l}12.3 \\
( \pm 1.8)\end{array}$ & $\begin{array}{l}12.2 \\
( \pm 1.7)\end{array}$ & $\begin{array}{l}12.2 \\
( \pm 1.6)\end{array}$ & $\begin{array}{l}12.0 \\
( \pm 1.5)\end{array}$ & $\begin{array}{l}11.9 \\
( \pm 1.5)\end{array}$ \\
\hline & AGulX & $\begin{array}{l}11.7 \\
( \pm 2.2)\end{array}$ & $\begin{array}{l}15.2 \\
( \pm 3.6)\end{array}$ & $\begin{array}{l}14.7 \\
( \pm 3.4)\end{array}$ & $\begin{array}{l}14.5 \\
( \pm 3.0)\end{array}$ & $\begin{array}{l}14.2 \\
( \pm 2.6)\end{array}$ & $\begin{array}{l}14.1 \\
( \pm 2.3)\end{array}$ & $\begin{array}{l}14.0 \\
( \pm 2.2)\end{array}$ & $\begin{array}{l}13.5 \\
( \pm 2.3)\end{array}$ & $\begin{array}{l}13.4 \\
( \pm 2.2)\end{array}$ & $\begin{array}{l}13.2 \\
( \pm 2.4)\end{array}$ & $\begin{array}{l}13.1 \\
( \pm 2.3)\end{array}$ \\
\hline & $\mathrm{p}$ & 0.65 & 0.03 & 0.03 & 0.02 & 0.02 & 0.02 & 0.01 & 0.07 & 0.06 & 0.09 & 0.06 \\
\hline
\end{tabular}

Values are given as means (+/-standard deviation).

(Mittelwerte $+/$-Standardabweichung) 
Table 4 Comparison of CNR between tumor and normal liver parenchyma of the two different contrast agents at different time points after contrast agent administration.

Tab. 4 Vergleich des CNR zwischen Tumoren und normalem Lebergewebe für beide Kontrastmittel zu unterschiedlichen Zeitpunkten.

$\begin{array}{lllllllllllll} & & \text { Unenh. } & \mathbf{2} \mathbf{m i n} & \mathbf{4} \mathbf{~ m i n} & \mathbf{6} \mathbf{m i n} & \mathbf{8} \mathbf{m i n} & \mathbf{1 0} \mathbf{m i n} & \mathbf{1 2} \mathbf{m i n} & \mathbf{1 4} \mathbf{m i n} & \mathbf{1 6} \mathbf{m i n} & \mathbf{1 8} \mathbf{~ m i n} & \mathbf{2 0} \mathbf{m i n} \\ \text { liver/ } & \text { Gd- } & -3.8 & -2.4 & -2.4 & -2.4 & -2.5 & -2.4 & -2.5 & -2.2 & -2.8 & -2.7 & -2.2 \\ \text { tumor } & \text { DOTA } & ( \pm 2.9) & ( \pm 3.1) & ( \pm 2.9) & ( \pm 3.7) & ( \pm 3.4) & ( \pm 3.3) & ( \pm 3.2) & ( \pm 3.6) & ( \pm 3.1) & ( \pm 3.2) & ( \pm 2.5) \\ & \text { AGulX } & -5.3 & -9.6 & -8.9 & -7.4 & -7.8 & -7.1 & -7.1 & -7.1 & -6.5 & -6.9 & -6.4 \\ & & ( \pm 4.3) & ( \pm 6.2) & ( \pm 5.6) & ( \pm 5.0) & ( \pm 4.6) & ( \pm 4.1) & ( \pm 4.4) & ( \pm 4.6) & ( \pm 4.8) & ( \pm 4.9) & ( \pm 5.0) \\ & & 0.27 & 0.005 & 0.004 & 0.01 & 0.006 & 0.004 & 0.004 & 0.006 & 0.03 & 0.02 & 0.03\end{array}$

Values are given as means (+/-standard deviation).

(Mittelwerte + /- Standardabweichung).

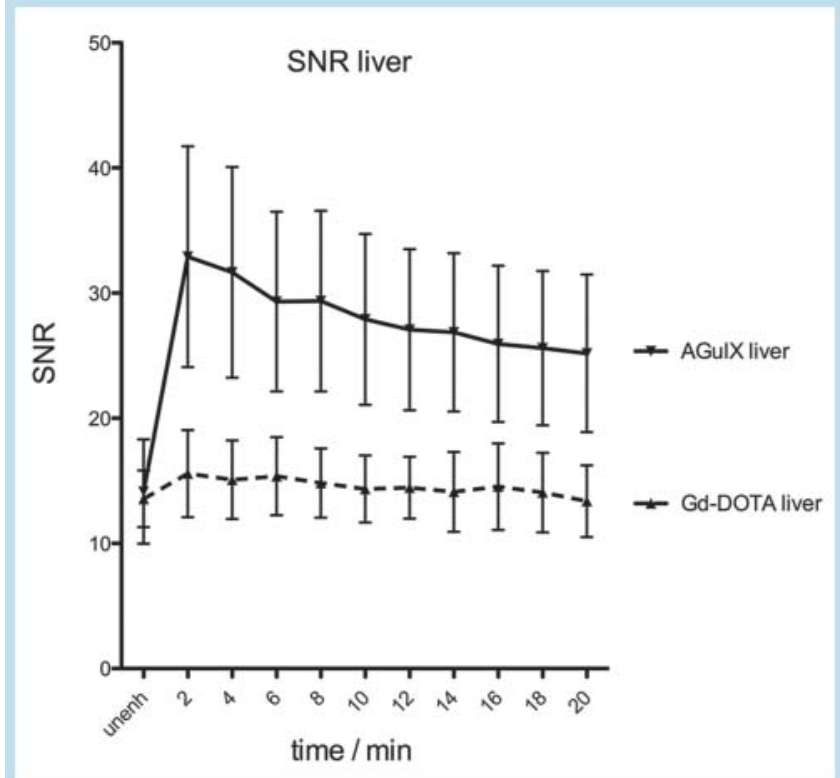

Fig. 5 SNR evolution of normal liver parenchyma using Gd-DOTA $(0.1 \mathrm{mmol} / \mathrm{kg} \mathrm{BW})$ and AGulX (0.01 mmol/ $\mathrm{kg} \mathrm{BW})$ at the different acquired time points. Data are given as means +/-SD.

Abb. 5 Zeitverlauf des SNR des normalen Lebergewebes nach Gabe von Gd-DOTA (0,1 mmol/kg Körpergewicht) und AGulX (0,01 mmol/kg Körpergewicht). Dargestellt sind Mittelwerte $+/$ - Standardabweichungen.

points). Both contrast agents reached the highest signal levels immediately after application followed by a continuous decrease during the remainder of the examination interval. In regard to the hypoenhancing aspects of the liver tumors, the SNR values were again significantly higher after application of AGuIX (SNR mean, tumor, hypoenhanc. (AGuIX): $15.4+/-0.7)$ as compared to Gd-

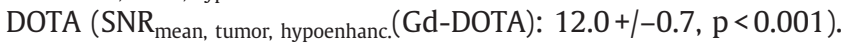
The SNR measurements of the muscle also revealed higher values after the injection of AGuIX ( $\mathrm{SNR}_{\text {mean, muscle }}$ (AGuIX): $14.0+\mid-0.7$ ) in contrast to Gd-DOTA ( $\mathrm{SNR}_{\text {mean, muscle }}(\mathrm{Gd}-\mathrm{DOTA}): 12.3+/-0.3$, $\mathrm{p}<0.001$ ).

The CNR values calculated as the difference between the SNR of normal liver tissue and the SNR of hypoenhancing aspects of the hepatic metastases were significantly different when applying AGuIX ( $\mathrm{CNR}_{\text {mean, tumor }}(\mathrm{AGuIX})$ : $\left.-7.5+/-1.0\right)$ compared to GdDOTA for equal doses of injected gadolinium $\left(\mathrm{CNR}_{\text {mean, tumor }}(\mathrm{Gd}-\right.$ DOTA): $-2.5+/-0.2 ; \mathrm{p}=0.004-0.03$ for all contrast-enhanced time points). Detailed CNR data are provided in $\bullet$ Table 4.

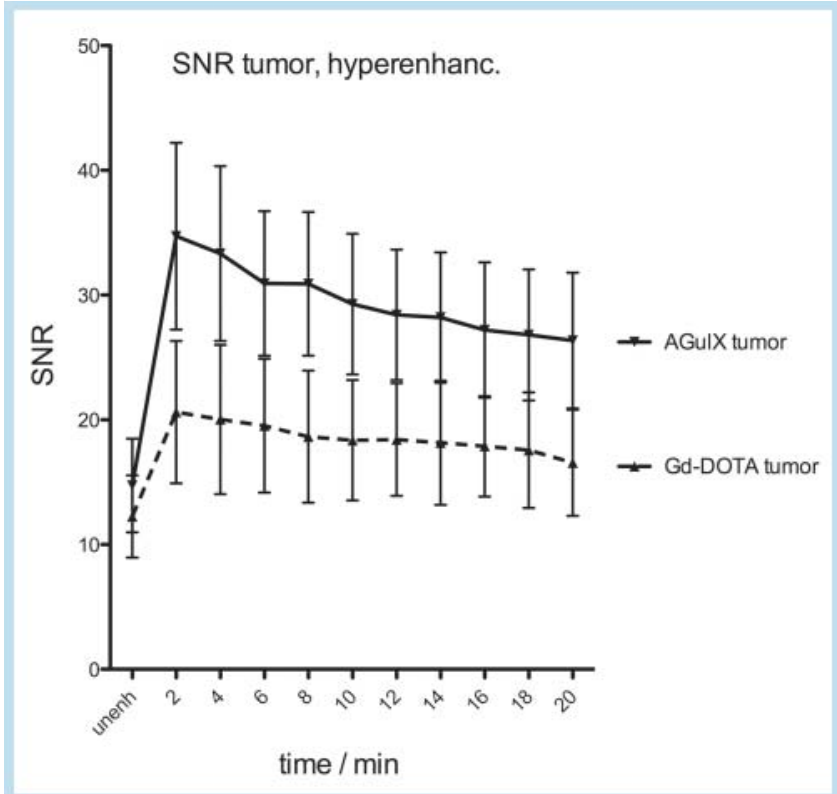

Fig. 6 SNR evolution of hyperenhancing aspects of the induced liver metastases using Gd-DOTA (0.1 mmol/kg BW) and AGulX (0.01 mmol/kg BW) at the different acquired time points. Data are given as means +/- SD.

Abb. 6 Zeitverlauf des SNR von stark kontrastmittelaffinen Anteilen der induzierten Lebermetastasen nach Gabe von Gd-DOTA ( 0,1 mmol/kg Körpergewicht) und AGulX (0,01 mmol/kg Körpergewicht). Dargestellt sind Mittelwerte +/- Standardabweichungen.

AGuIX provided significantly higher values of lesion enhancement ( $\mathrm{LE}_{\text {mean }}(\mathrm{AGuIX}): 14.9+/-2.8$ ) compared to Gd-DOTA (LE $\mathrm{Lean}_{\text {men }}$ (Gd-DOTA): $3.8+/-0.7$; $\mathrm{p}<0.001-0.003$ for all contrast-enhanced time points) again demonstrating an early peak of enhancement at the first examination time point with gradual washout during the examination period of 15 minutes. Detailed lesion enhancement data are provided in 0 Table 5 with representative graphs displayed in $\bullet$ Fig. 7.

\section{Discussion}

\section{$\nabla$}

In recent years marked efforts have been made in the field of nanotechnology to implement complexes for different biomedical applications, in particular to diagnose and treat diseases [12]. Especially in the field of diagnostic imaging, nanoparticles were expected to show a valuable advantage due to possible multifunctionality, serving as contrast agents for different imaging 
Table 5 Comparison of lesion enhancement (LE) of the two different contrast agents at different time points after contrast agent administration.

Tab. 5 Vergleich des Läsionenhancements (LE) für beide Kontrastmittel zu unterschiedlichen Zeitpunkten.

\begin{tabular}{|c|c|c|c|c|c|c|c|c|c|c|c|c|}
\hline & & Unenh. & $2 \min$ & $4 \mathrm{~min}$ & $6 \mathrm{~min}$ & $8 \mathrm{~min}$ & $10 \mathrm{~min}$ & $12 \mathrm{~min}$ & $14 \mathrm{~min}$ & $16 \mathrm{~min}$ & $18 \mathrm{~min}$ & $20 \mathrm{~min}$ \\
\hline \multirow[t]{3}{*}{ tumor } & $\begin{array}{l}\text { Gd- } \\
\text { DOTA }\end{array}$ & 0 & $\begin{array}{l}8.4 \\
( \pm 3.8)\end{array}$ & $\begin{array}{l}7.8 \\
( \pm 3.6)\end{array}$ & $\begin{array}{l}7.3 \\
( \pm 3.5)\end{array}$ & $\begin{array}{l}6.4 \\
( \pm 3.3)\end{array}$ & $\begin{array}{l}6.1 \\
( \pm 3.3)\end{array}$ & $\begin{array}{l}6.2 \\
( \pm 3.0)\end{array}$ & $\begin{array}{l}5.9 \\
( \pm 3.5)\end{array}$ & $\begin{array}{l}5.6 \\
( \pm 3.1)\end{array}$ & $\begin{array}{l}5.3 \\
( \pm 2.9)\end{array}$ & $\begin{array}{l}4.3 \\
( \pm 3.1)\end{array}$ \\
\hline & AGulX & 0 & $\begin{array}{l}20.0 \\
( \pm 5.4)\end{array}$ & $\begin{array}{l}18.6 \\
( \pm 5.0)\end{array}$ & $\begin{array}{l}16.2 \\
( \pm 5.0)\end{array}$ & $\begin{array}{l}16.2 \\
( \pm 5.3)\end{array}$ & $\begin{array}{l}14.6 \\
( \pm 5.0)\end{array}$ & $\begin{array}{l}13.7 \\
( \pm 4.3)\end{array}$ & $\begin{array}{l}13.5 \\
( \pm 4.2)\end{array}$ & $\begin{array}{l}12.5 \\
( \pm 4.6)\end{array}$ & $\begin{array}{l}12.1 \\
( \pm 4.4)\end{array}$ & $\begin{array}{l}11.6 \\
( \pm 4.6)\end{array}$ \\
\hline & p & $\mathrm{n} / \mathrm{a}$ & $<0.001$ & $<0.001$ & $<0.001$ & $<0.001$ & $<0.001$ & $<0.001$ & 0.002 & 0.003 & $<0.001$ & 0.002 \\
\hline
\end{tabular}

Values are given as means ( $+/-$ standard deviation).

Mittelwerte $+/$ - Standardabweichung.

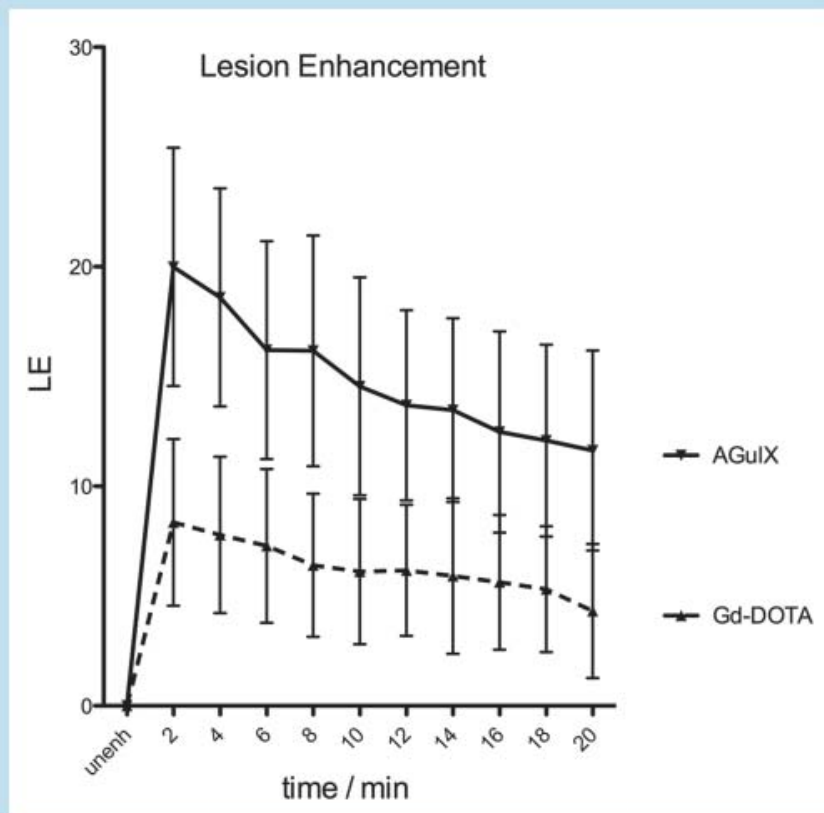

Fig. 7 Comparison of lesion enhancement (LE) between Gd-DOTA $(0.1 \mathrm{mmol} / \mathrm{kg} \mathrm{BW})$ and AGulX $(0.01 \mathrm{mmol} / \mathrm{kg} \mathrm{BW})$ at the different acquired time points. Data are given as means $+/$-SD.

Abb.7 Vergleich des Läsionsenhancements (LE) zwischen Gd-DOTA $(0,1 \mathrm{mmol} / \mathrm{kg}$ Körpergewicht) und AGulX $(0,01 \mathrm{mmol} / \mathrm{kg} \mathrm{KG})$ zu verschiedenen Zeitpunkten. Dargestellt sind Mittelwerte +/-Standardabweichungen.

modalities [7] while at the same time serving as therapeutics, i.e. for drug delivery, as radio-sensitizer, for the induction of hyperthermia, or for neutron therapy [4]. One important issue in this setting is the size of the designed nanoparticles; multifunctionality often requires linking particular side chains to the complexes, thereby increasing the molecular weight and the diameter to an inappropriate extent. This may result in an undesirable accumulation of the complexes in the body, i. e., by an unselective uptake in macrophages of the reticulo-endothelial system of the liver and the lung. This effect is particularly of importance for molecular diameters larger than $50 \mathrm{~nm}$ [4]. Thus, it is still challenging to ensure multifunctionality and biocompatibility while avoiding undesirable accumulation of the compounds $[13,14]$. Highly sophisticated technologies may provide silica or polymeric-based nanoparticles with a diameter between $2 \mu \mathrm{m}$ and $7 \mathrm{~nm}[6,15$, 16]. However, in order to allow for fast renal clearance from the body, particle diameters should be consistently below $5.5 \mathrm{~nm} \mathrm{[5].}$ The nanoparticle AGuIX evaluated in this study is a novel compound with a mean hydrodynamic diameter of $3.0+/-0.1 \mathrm{~nm}$ and a molecular weight of $8.5 \mathrm{kDa}$ consisting of a polysiloxane core grafted to $10 \mathrm{Gd}$-DOTA species in the periphery via amide functions [4]. Depending on the molecules chelated to the DOTA species (i.e., rare earth cations like gadolinium or radionuclides like ${ }^{111}$ Indium), AGuIX may serve as a contrast agent for MRI, CT, scintigraphy or optical imaging (in the latter by addition of organic fluorophore) [7]. Based on its small molecular size, AGuIX shows fast renal clearance from the body with a blood half-life time of 13.2 minutes and a hepatic uptake after intravenous application being as low as $0.15 \%$ [17].

Studies on Nuclear Magnetic Relaxation Dispersion (NMRD) profiles demonstrated high $\mathrm{r} 1$ relaxivities of AGuIX for a broad spectrum of field strengths. At $1.5 \mathrm{~T}$, it was quantified with $11.4 \mathrm{mM}^{-1}$ $\mathrm{sec}^{-1}$ per gadolinium atom as compared to Gd-DOTA with 3.6 $\mathrm{mM}^{-1} \sec ^{-1}[7,9,10]$. With an increasing field strength, the $\mathrm{r} 1 \mathrm{re}-$ laxivity of AGuIX demonstrates a continuous decrease, which is a common finding in Gd-based contrast agents with high molecule masses and diameters [8]. Yet, with $5.8 \mathrm{mM}^{-1} \mathrm{sec}^{-1}$ at $9.4 \mathrm{~T}$, it is still almost twice as high as the $\mathrm{r} 1$ relaxivity of Gd-DOTA.

Not surprisingly, AGuIX has been shown to demonstrate marked enhancement in an MRI in-vivo study in a rat brain glioma model, mainly attributable to the higher $\mathrm{r} 1$ relaxivity but also to the longer residence time of the complex in the brain tumors as compared to standard gadolinium compounds with extracellular distribution $[7,18,19]$.

Yet, no studies have been carried out so far to analyze AGuIX as an MR contrast agent for abdominal imaging. The results of our study show that AGuIX is an effective contrast agent for MRI of the liver in this rat model of hepatic colorectal cancer metastasis. It demonstrated a significantly higher SNR of normal liver tissue and hepatic tumors as well as a significantly higher CNR and lesion enhancement as compared to Gd-DOTA for equal doses of applied gadolinium. These markedly higher levels of enhancement for AGuIX may be explained by a decrease of the molecular tumbling rate of AGuIX due to the larger size and the rigidity of the structure as compared to the extracellular agent. Subsequently, this improves the interaction of water protons with the chelated gadolinium thus resulting in a higher relaxivity [20 - 22].

Regarding the contrast enhancement evolution, AGuIX demonstrates kinetics comparable to the extracellular compound GdDOTA with an early peak of enhancement and a gradual washout during the remainder of the examination period of 20 minutes. This is mainly attributable to the fast renal clearance of AGuIX and the lack of accumulation in the RES. This was confirmed by recently performed studies on biodistribution of the nanoparticle revealing an almost exclusive clearance from the body by renal excretion with a rate of $90 \%$ of AGuIX being eliminated within the first 24 hours after intravenous injection [22]. 
When applied in brain MRI, AGuIX does not cross the intact blood-brain barrier. Thus, normal brain tissue does not demonstrate any notable enhancement [7]. However, as demonstrated in this study, AGuIX showed marked enhancement for both normal liver tissue and hepatic metastases. This is based on the unique anatomical architecture of the liver in which fenestrations and discontinuity of the endothelium of the sinusoids and the lack of basement membranes facilitate the exchange of even large molecules or plasma proteins between the intravascular space and the extracellular compartment, in particular the perisinusoidal space (space of Disse) [18].

Some important points regarding the distribution of the nanoparticle in the hepatic lesions need to be addressed. As notable in the representative contrast-enhanced images in $\bullet$ Fig. 3 , the metastasis does not demonstrate homogeneous enhancement as can be frequently seen in brain metastases but rather demonstrates a heterogeneous signal with hypointense and hyperintense parts. This resembles the situation in humans, where hepatic metastases of colorectal cancer may be visualized with so-called "target signs" on contrast-enhanced MR images with circle-like, alternating hypo- and hyperintense parts. As the CNR between the normal liver tissue and the hypoenhancing parts of the liver lesions was significantly higher using AGuIX, the nanoparticle may contribute to lesion detection and conspicuity in hypovascular hepatic metastases. On the other hand, the SNR values of hyperenhancing tumor aspects were also significantly higher using AGuIX as compared to Gd-DOTA, which might be beneficial for the detection of hypervascular liver lesions such as hepatocellular carcinomas or metastases from neuroendocrine tumors. In addition, AGuIX demonstrated significant enhancement in other pathologic lesions, like brain gliomas and thus, may be considered a contrast agent with passive tissue distribution with enhanced permeability and retention (EPR) effects [23].

Besides pharmacokinetics, toxicity plays an important role for novel contrast agents. In recent studies, the immunotoxicity of AGuIX was evaluated in-vitro by incubating the nanoparticle with dendritic cells and complementary factors. Here, no evidence of toxicity could be found for concentrations of $1 \mathrm{mM}$ and $5 \mathrm{mM}$ Gd [24]. Furthermore, evaluation of the complexation constant of AGuIX revealed that the ability to bind $\mathrm{Gd}^{3+}$ by the DOTA species linked to the small rigid platform core is almost as high as compared to DOTA alone (see also $\bullet$ Table 1 ). Thus, the structure of AGuIX sufficiently prevents an undesirable release of gadolinium after in vivo application [4].

\section{Clinical Relevance}

- AGuIX is a new Gd-based nanoparticle with fast renal clearance and without accumulation in the reticulo-endothelial system.

- AGuIX provides superior enhancement properties for MRI of focal liver lesions at an ultrahigh field strength as compared to a standard extracellular contrast agent. This may potentially improve the detection of malignant liver lesions.

- Further studies need to demonstrate whether multifunctionality of AGuIX including radio-sensitizing and multimodal imaging contrast may be beneficial in hepatic malignancies.

\section{References}

1 Petros RA, DeSimone JM. Strategies in the design of nanoparticles for therapeutic applications. Nat Rev Drug Discov 2010; 9: 615-627

2 Cuenca AG, Jiang H, Hochwald SN et al. Emerging implications of nanotechnology on cancer diagnostics and therapeutics. Cancer 2006; 107: 459-466

3 Kim J, Piao Y, Hyeon T. Multifunctional nanostructured materials for multimodal imaging, and simultaneous imaging and therapy. Chem Soc Rev 2009; 38: $372-390$

4 Mignot A, Truillet C, Lux F et al. A top-down synthesis route to ultrasmall multifunctional Gd-based silica nanoparticles for theranostic applications. Chemistry 2013; 19: 6122-6136

5 Choi HS, Liu W, Misra P et al. Renal clearance of quantum dots. Nat Biotechnol 2007; 25: 1165-1170

6 Benezra M, Penate-Medina O, Zanzonico PB et al. Multimodal silica nanoparticles are effective cancer-targeted probes in a model of human melanoma. J Clin Invest 2011; 121: 2768-2780

7 Lux F, Mignot A, Mowat P et al. Ultrasmall rigid particles as multimodal probes for medical applications. Angew Chem Int Ed Engl 2011; 50: $12299-12303$

8 Fries P, Morelli JN, Lux F et al. The issues and tentative solutions for contrast-enhanced magnetic resonance imaging at ultra-high field strength. Wiley Interdiscip Rev Nanomed Nanobiotechnol 2014; 6: $559-573$

9 Noebauer-Huhmann IM, Szomolanyi P, Juras V et al. Gadolinium-based magnetic resonance contrast agents at 7 Tesla: in vitro T1 relaxivities in human blood plasma. Invest Radiol 2010; 45: 554-558

10 Rohrer M, Bauer H, Mintorovitch J et al. Comparison of magnetic properties of MRI contrast media solutions at different magnetic field strengths. Invest Radiol 2005; 40: 715-724

11 Reeder SB, Wintersperger BJ, Dietrich O et al. Practical approaches to the evaluation of signal-to-noise ratio performance with parallel imaging: application with cardiac imaging and a 32-channel cardiac coil. Magn Reson Med 2005; 54: 748 - 754

12 Monsky WL, Vien DS, Link DP. Nanotechnology development and utilization: a primer for diagnostic and interventional radiologists. Radiographics 2011; 31: 1449-1462

13 Cai $W$, Chen K, Li ZB et al. Dual-function probe for PET and near-infrared fluorescence imaging of tumor vasculature. J Nucl Med 2007; 48: $1862-1870$

14 Alric C, Taleb J, LeDuc G et al. Gadolinium chelate coated gold nanoparticles as contrast agents for both X-ray computed tomography and magnetic resonance imaging. J Am Chem Soc 2008; 130: 5908-5915

15 Green DL, Lin JS, Lam YF et al. Size, volume fraction, and nucleation of Stober silica nanoparticles. J Colloid Interface Sci 2003; 266: 346-358

16 Stöber W, Fink A, Bohn E. Controlled growth of monodisperse silica spheres in the micron size range. J Colloid Interface Sci 1968; 26: 62 - 69

17 Bianchi A, Lux F, Tillement $O$ et al. Contrast enhanced lung MRI in mice using ultra-short echo time radial imaging and intratracheally administrated Gd-DOTA-based nanoparticles. Magn Reson Med 2013; 70: $1419-1426$

18 Miladi I, Le Duc G, Kryza D et al. Biodistribution of ultra small gadolinium-based nanoparticles as theranostic agent: Application to brain tumors. J Biomater Appl 2013; 28: 385-394

19 Le Duc G, Miladi I, Alric C et al. Toward an image-guided microbeam radiation therapy using gadolinium-based nanoparticles. ACS Nano 2011; 5: 9566-9574

20 Henig J, Toth E, Engelmann J et al. Macrocyclic Gd3+ chelates attached to a silsesquioxane core as potential magnetic resonance imaging contrast agents: synthesis, physicochemical characterization, and stability studies. Inorg Chem 2010; 49: 6124-6138

21 Ananta JS, Godin B, Sethi R et al. Geometrical confinement of gadolinium-based contrast agents in nanoporous particles enhances T1 contrast. Nat Nanotechnol 2010; 5: 815-821

22 Voisin P, Ribot EJ, Miraux $S$ et al. Use of lanthanide-grafted inorganic nanoparticles as effective contrast agents for cellular uptake imaging. Bioconjug Chem 2007; 18: 1053 -1063

23 Martinez-Hernandez A, Amenta PS. The hepatic extracellular matrix. I. Components and distribution in normal liver. Virchows Arch A Pathol Anat Histopathol 1993; 423: 1-11

24 Ferrari $M$. Cancer nanotechnology: opportunities and challenges. Nat Rev Cancer 2005; 5: 161 -171 